\title{
THE ROLE OF LINGO-1 AND MYELIN BASIC PROTEIN MRNAS IN CENTRAL REMYELINATION IN ETHIDIUM BROMIDE-INDUCED DEMYELINATION IN RATS
}

\author{
HANAA ABOELKASEM ALAZRAG ${ }^{1 *}$, MERVAT EID ABDELGHAFFAR ${ }^{1}$, HUDA MAHMOUD KHALIFA ${ }^{2}$, \\ RASHA MOHAMED ADEL NASSRA ${ }^{3}$, AMANY ALI KHALIL NAWAR ${ }^{1}$
}

${ }^{1}$ Department of Clinical Pharmacology, Faculty of Medicine, Alexandria University, Egypt. ${ }^{2}$ Department of Histology and Cell Biology, Faculty of Medicine, Alexandria University, Egypt. ${ }^{3}$ Department of Medical Biochemistry, Faculty of Medicine, Alexandria University, Egypt. Email: Hanaalazrag@yahoo.com

Received: 01 September 2019, Revised and Accepted: 30 September 2019

ABSTRACT

Objective: The study aimed to assess the possible role of quercetin, pioglitazone, metformin, and dapagliflozin in the enhancement of remyelination process after ethidium bromide (EB)-induced demyelination.

Methods: The study was conducted on 60 male Wister rats (250-300 g), randomly divided into sham-operated group and five demyelination groups (each of 10 rats) which subjected to intrapontine stereotaxic injection of $\mathrm{EB}(10 \mu \mathrm{l}$ of $0.1 \% \mathrm{~EB})$ to induce demyelination. Then, randomly subdivided into: $\mathrm{EB}$ control group: Rats were treated with normal saline, quercetin-treated group (50 mg/kg/day), pioglitazone-treated group (10 mg/kg/day), metformin-treated group $(500 \mathrm{mg} / \mathrm{kg} /$ day), and dapagliflozin-treated group (10 mg/kg/day). Behavioral tests (beam balance, foot fault, rotarod, and inverted screen) were conducted for all groups as well as biochemical analysis of LINGO-1 and myelin basic protein (MBP) mRNAs and histological examination of pontine tissues.

Results: The EB control group showed deterioration of motor performance on behavioral tests. Degenerative changes were observed in pontine tissue on histological examination together with upregulation of LINGO-1 protein and downregulation of MBP level. While the treated groups after EB demyelination showed significant improvement in motor performance and decreased degenerated neurons in histological examination with upregulation of MBP level and downregulation of LINGO-1 protein level.

Conclusion: Quercetin, metformin, dapagliflozin, and pioglitazone showed neuroprotective effect and enhancement of remyelination process.

Keywords: Remyelination, Myelin basic protein, Multiple sclerosis, Oligodendrocyte.

(c) 2019 The Authors. Published by Innovare Academic Sciences Pvt Ltd. This is an open access article under the CC BY license (http://creativecommons. org/licenses/by/4. 0/) DOI: http://dx.doi.org/10.22159/ajpcr.2019.v12i11.35555

\section{INTRODUCTION}

Multiple sclerosis is a debilitating disease of the central nervous system (CNS), typically presents in the third or fourth decade of life. It is estimated that more than 2 million people have MS worldwide and is considered to be one of the most common causes of neurological disability affecting mainly young adults with a predominant presentation in young women [1].

The adult CNS has a limited capacity to repair damaged tissue, and this restriction is related to neurons plus their axons and also mature oligodendrocytes that are unable to compensate for myelin loss as they degenerate [2]. This demyelination process usually triggers a spontaneous myelin repair process, known as remyelination [3].

Research on the treatment of MS is directed at three main goals: Preventing the development of new demyelinating lesions, protecting demyelinated axons from degeneration, and promoting remyelination [4]. Each phase of remyelination is regulated by a complex pattern of signaling events, the dysregulation of which will result in remyelination impairment [5].

Induction of demyelination by ethidium bromide (EB) is one of the most commonly used experimental models for understanding the cellular changes that occur during MS [6]. The toxic effects of EB are due to its DNA intercalating properties; it affects all nucleated cells and destroys astrocytes and oligodendrocytes throughout the demyelinated area [7].

Quercetin is a flavonoid with antioxidant capacity that is present in a variety of vegetables and fruits that are consumed in diet [8].
Metformin is dimethylguanylguanidine [9]. It has several properties that are desired for MS therapy as anti-inflammatory [10] and antioxidant properties [11].

Pioglitazone is an antidiabetic agent belonging to the thiazolidinedione group. It is a selective peroxisome proliferator-activated receptor (PPAR)- $\gamma$ agonist. PPAR- $\gamma$ has high expression levels in brown and white adipose tissues, brain, colon, differentiated myeloid cells, and the placenta [12].

Dapagliflozin is a selective inhibitor of sodium/glucose cotransporter-2 (SGLT2) approved for the treatment of type 2 diabetes, by interfering with renal glucose reabsorption to control hyperglycemia independent of pancreatic $\beta$-cell function [13].

\section{METHODS}

Experimental animals

This study was conducted on 60 adult male Wister rats, weighting 250-300 g. They were housed in stainless steel wire meshed cages under environmentally controlled conditions. The ambient temperature was $25 \pm 2^{\circ} \mathrm{C}$ and the light/dark cycle was $12 / 12 \mathrm{~h}$. The animals had free access to water and food at the Animal House of the Faculty of Medicine, Alexandria University.

All experiments were carried out according to the Guide for the Care and Use of Laboratory Animals and were approved by the Medical Ethics Committee of Faculty of Medicine, Alexandria University.

\section{Chemicals and drugs}

EB (from Medico Pharm Company), quercetin (10 g., Medico Pharm), pioglitazone (30 m Amoun Pharmaceutical Company S.A.E), metformin 
(500 mg Minapharm), and dapagliflozin (10 mg AstraZeneca) were used.

\section{Experimental design and procedures}

The rats were classified into two groups:

1. Sham group: It included 10 rats that received a single intrapontine injection of $10 \mu \mathrm{l}$ of saline $(0.9 \% \mathrm{NaCl})$.

2. Demyelination group: It included 50 rats that were received a single injection of $10 \mu \mathrm{l}$ of $0.1 \%$ EB [14] intrapontine. Then, they were further randomly subdivided into five subgroups 10 rats each.

- EB control group: Rats were treated with normal saline orally daily for 3 weeks.

- Quercetin-treated group: Rats were treated with quercetin at a dose of $50 \mathrm{mg} / \mathrm{kg} /$ day [15].

- Metformin-treated group: Rats were treated with metformin at a dose of $500 \mathrm{mg} / \mathrm{kg} /$ day [16]

- Dapagliflozin-treated group: Rats were treated with dapagliflozin at a dose of $10 \mathrm{mg} / \mathrm{kg} /$ day [17].

- Pioglitazone-treated group: Rats were treated with pioglitazone at a dose of $10 \mathrm{mg} / \mathrm{kg} /$ day [18].

All drugs were dissolved in $1 \%(\mathrm{w} / \mathrm{v})$ methylcellulose (USP grade, Sigma-Aldrich) as vehicle and given daily for 3 weeks.

All rats were sacrificed by decapitation on the $21^{\text {st }}$ day of the experiment.

\section{Stereotaxic surgery}

Rats were anesthetized by a mixture of ketamine and xylazine (80$100 \mathrm{mg}$ ketamine and $10 \mathrm{mg}$ xylazine per $\mathrm{kg}$ body weight) injected intraperitoneally. Then, each animal was fixed in the stereotaxic frame (Kopf, Germany) with the incisor bar set at $-3.3 \mathrm{~mm}$ to adjust head level. Lubricant eye ointment was applied to prevent corneal drying during the surgery [19]. Demyelination was induced by intrapontine stereotaxic injection of EB. The following coordinates were used: $9.16 \mathrm{~mm}$ posterior, $9 \mathrm{~mm}$ ventral, and $1.4 \mathrm{~mm}$ lateral to the bregma according to the Atlas of Paxinos and Watson [20]. The skull over the target area was drilled using a handheld drill. With the use of a 28-gauge Hamilton microsyringe, $10 \mu \mathrm{l}$ of $0.1 \%$ EB was injected [14]. The needle was kept in place for an additional $10 \mathrm{~min}$ after injection to prevent potential "back-leakage." Upon needle removal, the skin together with remainder of the subcutaneous tissue was sutured with a nylon thread 4.0, and the animals were allowed to recover [21].

\section{Neurological and behavioral tests}

The rats will be submitted to the evaluation of clinical signs on the $7^{\text {th }}$ and $21^{\text {st }}$ days after EB injection in control and demyelination groups, to prove the occurrence of demyelination, and to detect the effect of treatment.

All behavioral tests were conducted by researchers blind to group identity.

\section{Beam balance test}

It is used to assess balance and fine motor coordination. Each rat was placed on an elevated horizontal beam $(25 \mathrm{~mm}$ in diameter, $59 \mathrm{~cm}$ in length). During the test, thoracic and pelvic limbs of rats were evaluated, different scores were given as follows: 0 - "normal:" Foot positioned on top of the beam, no slippage and 1 - "error:" Whole foot slipped below the lower surface of the beam [22].

\section{Foot fault test}

This test consists of placing the rat on an elevated grid floor $(40 \times 40 \mathrm{~cm})$ with grid openings $3 \mathrm{~cm}^{2}$. Rats placed their paws on the wireframe while moving along the grid. The test was recorded when the paw fell or slipped through the wire, during each weight-bearing step. Every rat performed a total number of 50 steps and during these, the number of foot faults was recorded [23].
Rotarod test

It assesses motor functions, gross coordination, and motor learning. It consists of a rotating drum that can be accelerated from 4 to 40 revolutions per minute over the course of 5 min. All rats were trained on the rotarod for 5 trials/day for 3 days. Each rat was placed individually on the drum and the latency of falling down from the drum was recorded [24].

\section{Inverted screen test}

It is a test of muscle strength using all four limbs. The screen was a $43 \mathrm{~cm}^{2}$ of wire mesh consisting of $12 \mathrm{~mm}$ squares of $1 \mathrm{~mm}$ diameter wire. Rats were placed in the center of the wire mesh screen, a stopwatch was started, and the screen was rotated to inverted position over $2 \mathrm{~s}$. The screen should be held steadily $40-50 \mathrm{~cm}$ above a padded surface. The time when the rat fell off was recorded and scored as follows: Falling between 1 and $10 s=1$, falling between 11 and $25 \mathrm{~s}=2$, falling between 26 and $60 \mathrm{~s}=3$, and falling after $60 \mathrm{~s}=4$ [25].

\section{Extraction of brain tissue}

After completion of behavioral assessment at the $21^{\text {st }}$ day post-surgery, rats were decapitated under deep thiopental sodium anesthesia. The brain was isolated and washed with phosphate-buffered saline solution at $\mathrm{pH} 7.4$, to remove any red blood cells and clots. Pontine tissue samples were collected and stored in RNA later reagent (Qiagen) at a temperature of $-80^{\circ} \mathrm{C}$ for the assessment of LINGO-1 and myelin basic protein (MBP) mRNAs expression levels.

\section{Relative quantification of LINGO-1 and MBP gene expression by} real-time quantitative polymerase chain reaction (RT-qPCR) Total RNA extraction

Total RNA, including mRNA, was extracted from pontine tissue samples (30 mg) using RNeasy Mini Kit and following the manufacturer's protocol (Qiagen). All steps were performed under strictly sterile and RNAse-free conditions at room temperature $\left(15-25^{\circ} \mathrm{C}\right)$. RNA was ethanol precipitated, resuspended in RNase-free water and the assessment of the concentration and purity of the extracted RNA samples were determined at 260-280 nm using Nanodrop 2000/2000c spectrophotometer (Thermo Scientific, USA). RNA samples were stored at $-80^{\circ} \mathrm{C}$ until further processing [26].

\section{Complementary DNA (cDNA) synthesis}

Reverse transcription (RT) of purified RNA was performed in $25 \mu \mathrm{L}$ reaction volume with $100 \mathrm{ng}$ of total RNA, random hexamer primer, and RT Superscript II (Invitrogen, USA).

\section{$R T-P C R$}

The RT-PCR measurement of LINGO-1 and MBP cDNA was performed using the one-step RT-PCR system (Applied Biosystems, USA). Amplification of the synthesized cDNAs was performed in duplicates in a $25 \mu \mathrm{l}$ reaction volume containing $1 \mathrm{X}$ SYBR $®$ Green PCR Master Mix (Applied Biosystems, USA). The specific primer pair for LINGO-1 was the sense primer AGAGACATGCGATTGGTGA and the antisense primer AGAGATGTAGACGAGGTCATT (GenBank accession number AAH11057). As for MBP, specific primer pair was the sense primer GGCAAGGACTCACACACAAGAA and the antisense primer CTTGGGTCCTCTGCGACTTC (GenBank accession number AC 000086). The amplification consisted of one cycle at $95^{\circ} \mathrm{C}$ for $30 \mathrm{~s}$ followed by 40 cycles of denaturation at $95^{\circ} \mathrm{C}$ for $5 \mathrm{~s}$, a $60^{\circ} \mathrm{C}$ (for LINGO-1) or $64^{\circ} \mathrm{C}$ (for MBP) annealing step for $10 \mathrm{~s}$, and an extension step at $72^{\circ} \mathrm{C}$ for $20 \mathrm{~s}[27,28]$.

For verification of the correct amplification product, the PCR products were analyzed on $2 \%$ agarose gel stained with EB. In addition, PCR amplification was followed by a melting curve analysis where the identity of the PCR product was confirmed. A negative control without cDNA was run with every PCR. Glyceraldehyde-3-phosphate dehydrogenase (GAPDH) was used as a normalization gene [29]. 


\section{Histological examination}

Pontine tissue specimens were placed in osmic stain solution. For $\mathrm{H}$ and $\mathrm{E}$ stain, specimens were placed in $10 \%$ neutral formalin solution. Coronal sections of pons ( $5 \mu \mathrm{m}$ thick) were cut and stained with osmic stain and hematoxylin and eosin ( $\mathrm{H}$ and $\mathrm{E}$ ) stain, then analyzed using a light microscope.

\section{Data analysis}

Data were fed to the computer and analyzed using IBM SPSS software package version 20.0. (Armonk, NY: IBM Corp). Analysis of the data was performed using StepOne ${ }^{\mathrm{TM}}$ software v2.3 where the level of expression of LINGO-1 and MBP was determined by the comparative Ct method and presented as fold change relative to the housekeeping gene (GAPDH).

The Kolmogorov-Smirnov test was used to verify the normality of distribution.
Quantitative data were described using range (minimum and maximum), mean, standard deviation, and standard error of mean and median. The significance of the obtained results was judged at $5 \%$ level.

The used tests were F-test (ANOVA) for normally distributed quantitative variables, to compare between more than two groups and post hoc test (Tukey) for pairwise comparisons.

\section{RESULTS}

Effect of different treated drugs on motor performance

EB injection resulted in significant impairment of motor performance as shown by a significant reduction in mean latency to fall in rotarod test in the EB control group both in the $7^{\text {th }}$ and $21^{\text {st }}$ days $(37.33 \pm 16.69$ and $46.87 \pm 10.45$ compared to $144.7 \pm 7.97$ and $146.21 \pm 6.55$ for the

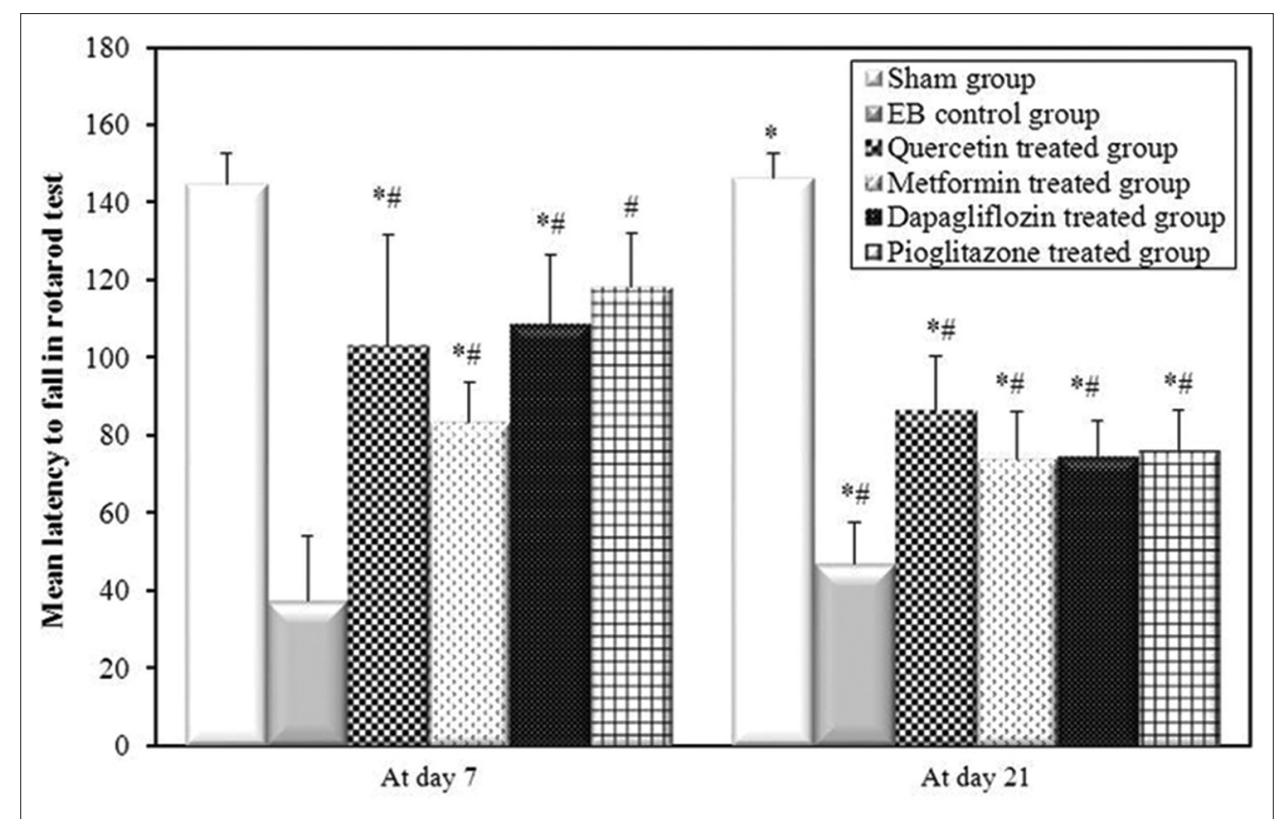

Fig. 1: Mean latency to fall in the rotarod test in rats of the different studied groups. *: Significant with sham, \#: Significant with control, $*$ : Statistically significant at $\mathbf{p} \leq \mathbf{0 . 0 5}$

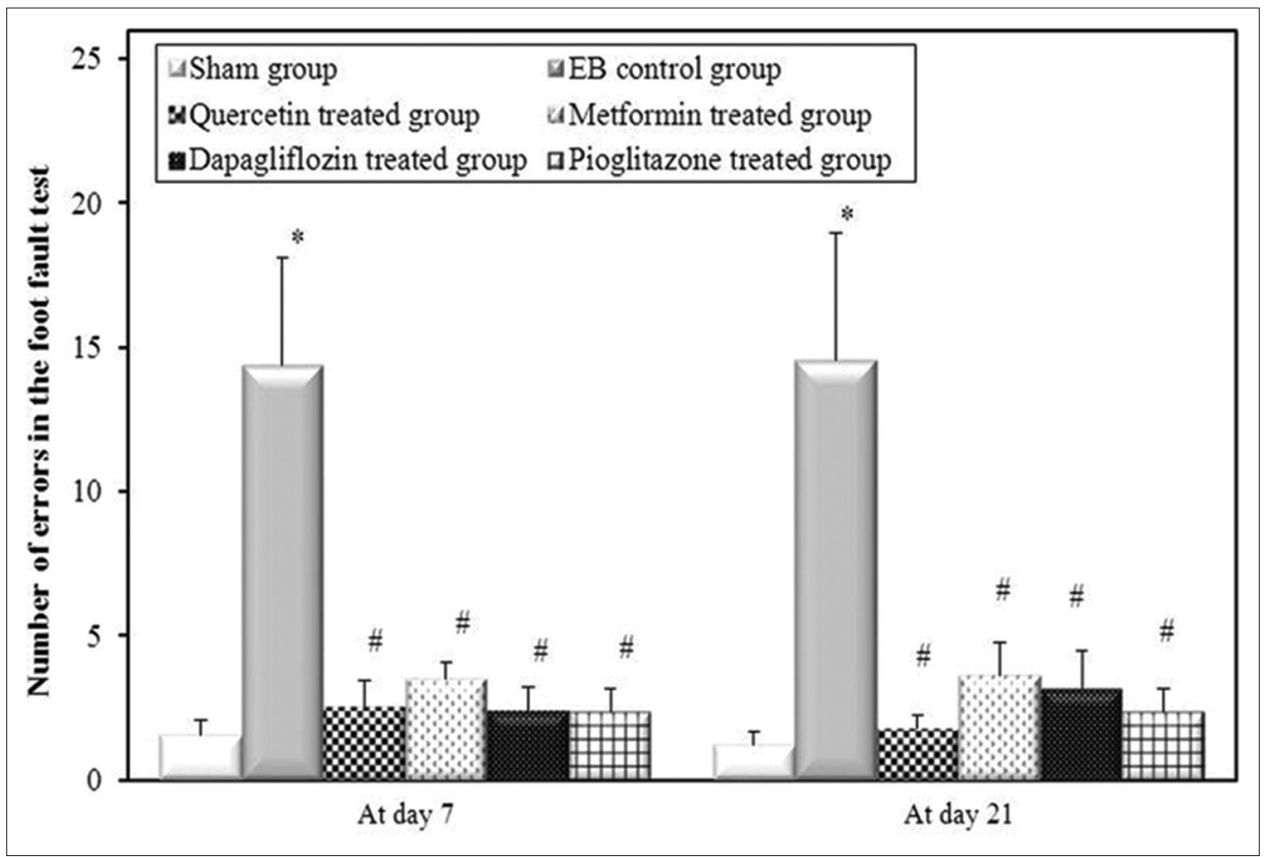

Fig. 2: Number of errors in the foot fault test in rats of the different studied groups. *: Significant with sham, \#: Significant with ethidium bromide 


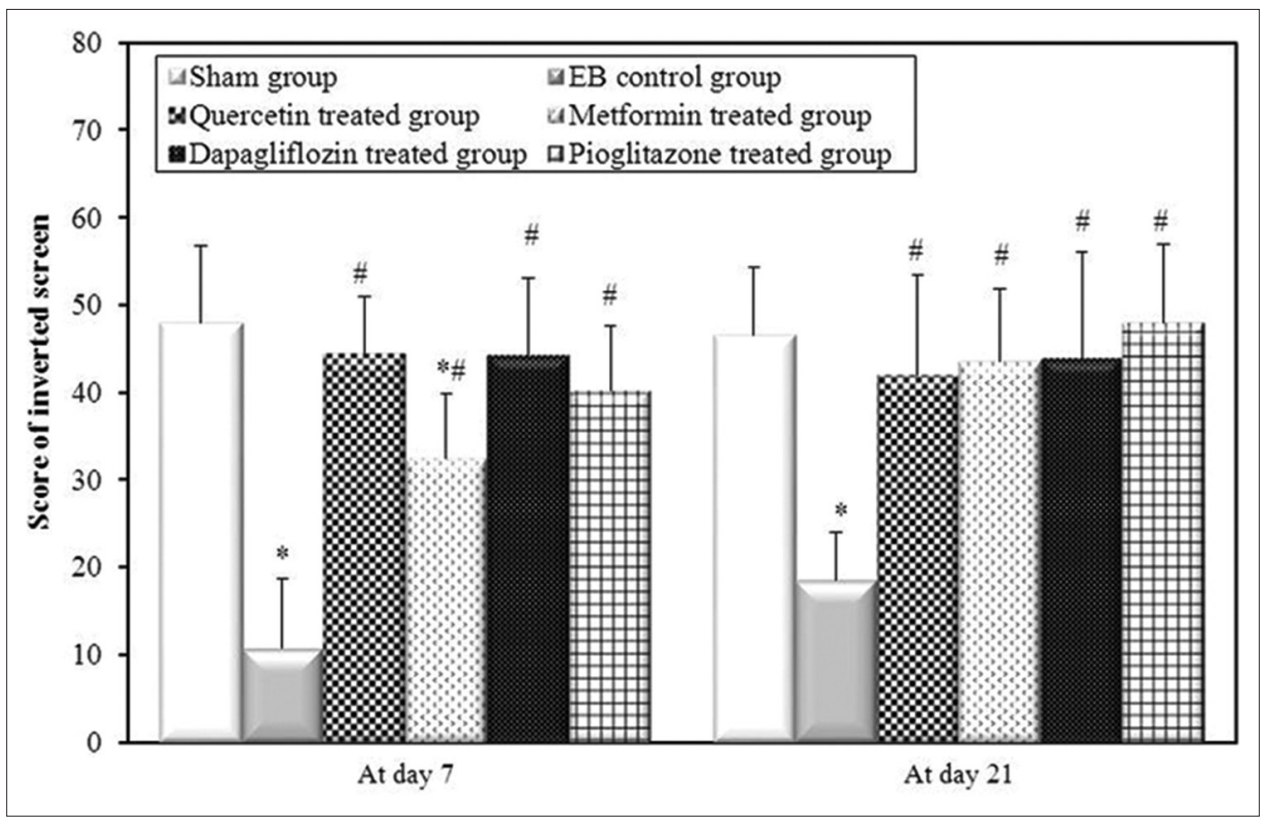

Fig. 3: Score of inverted screen test in rats of the different studied groups. *: Significant with sham, \#: Significant with ethidium bromide

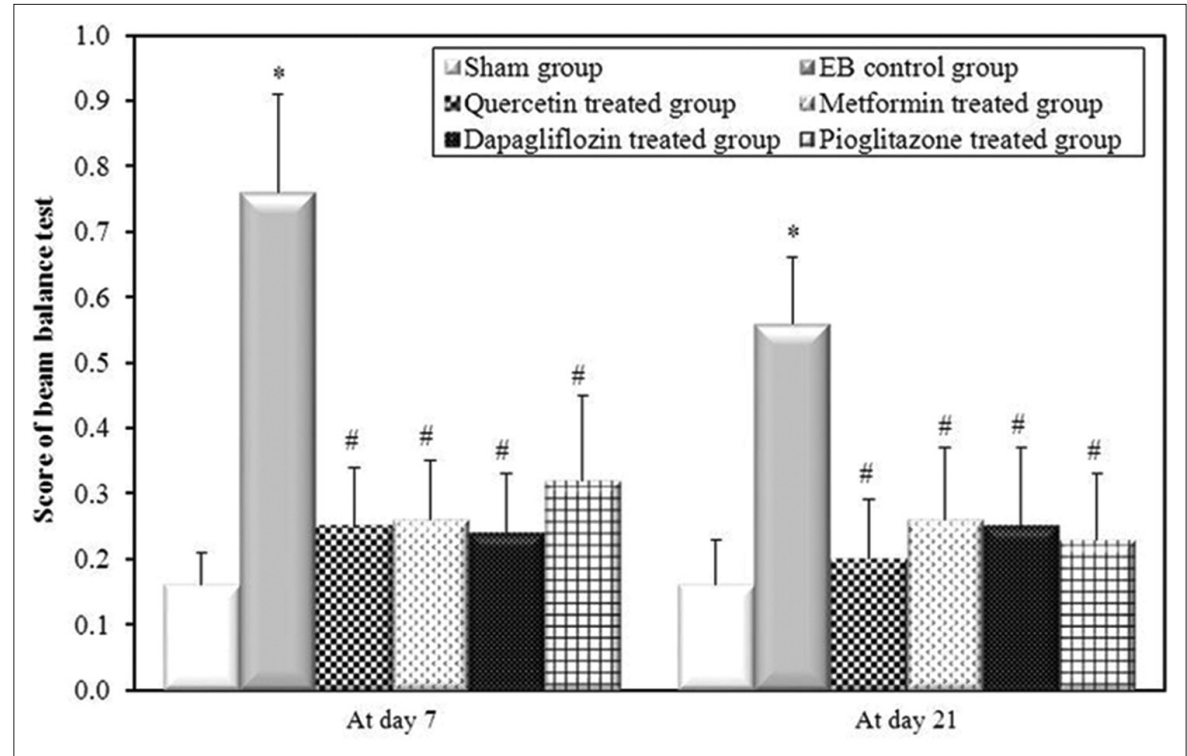

Fig. 4: Score of the beam balance test in rats of the different studied groups. *: Significant with sham, \#: Significant with ethidium bromide
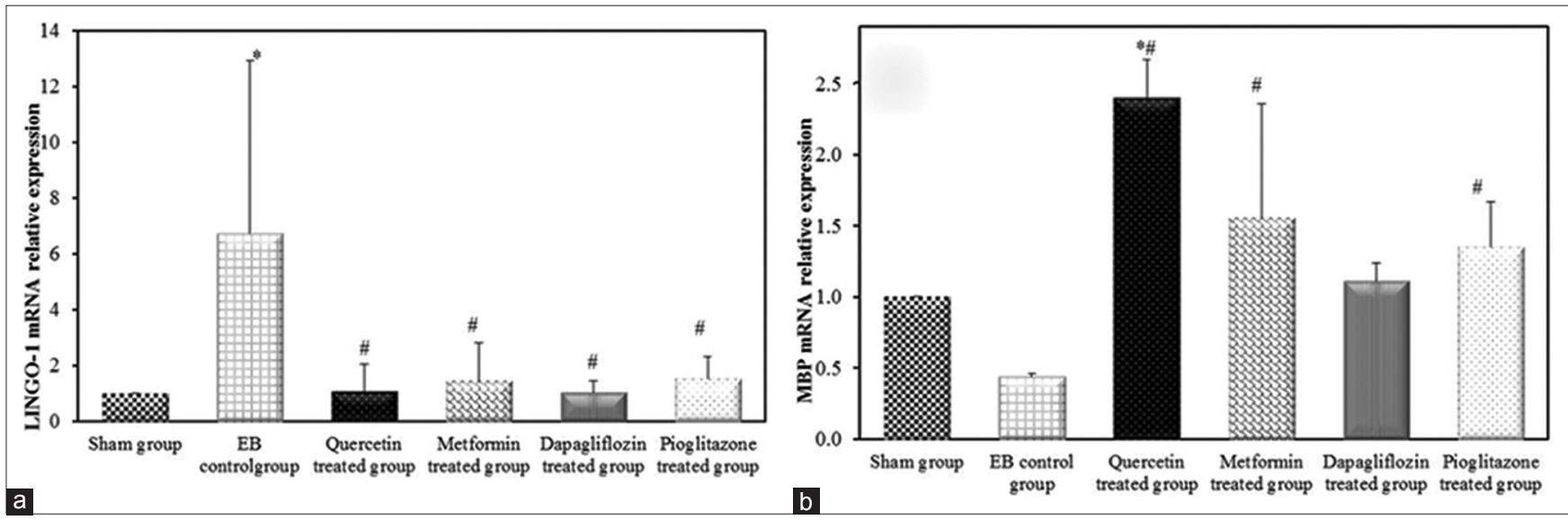

Fig. 5: Effect of drug treatment on (a) LINGO-1 mRNA expression, (b) myelin basic protein mRNA expression in pontine tissue. *: Significant with sham, \#: Significant with ethidium bromide 


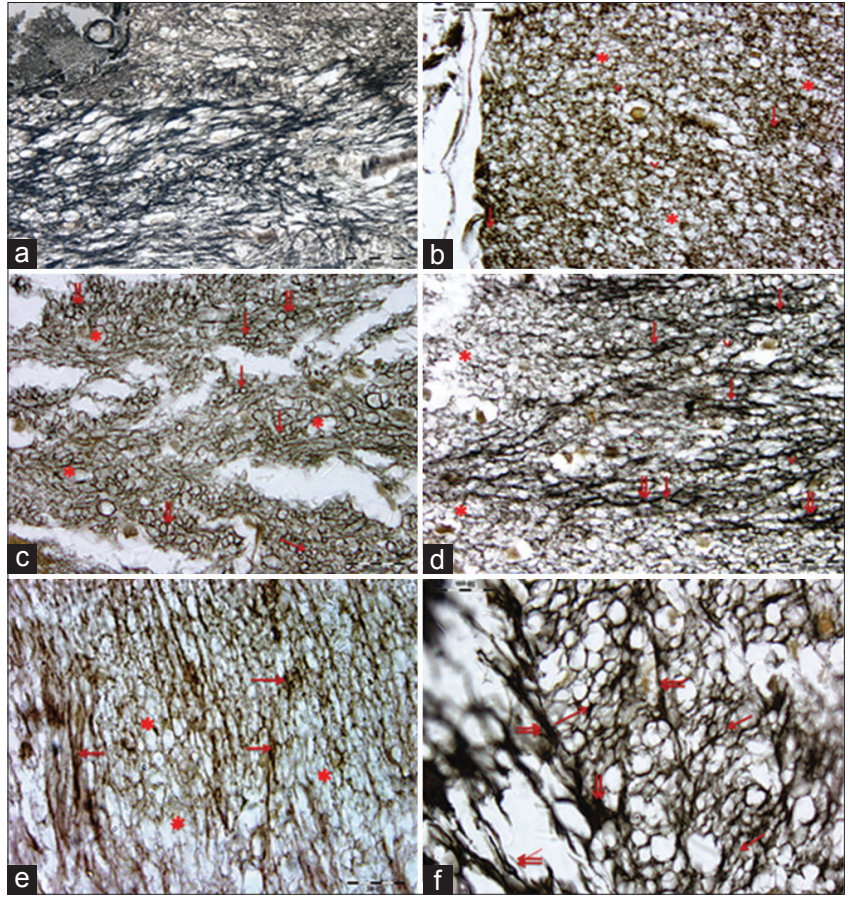

Fig. 6: Photomicrographs of the white matter of the pontine tissue showing: (a) The classical structure with longitudinal and transverse sections of bundles of densely stained uniform regular large axon with thick myelin sheathes of variable diameter in sham control rats. (b) Demyelinated group revealing weakly stained irregular myelin sheathes with incompletely myelinated fibers (arrow head). Most of the nerve fibers show swelling vacuolation with narrowing of the space in between. Many areas of dissolution demyelinated nerve fibers $\left({ }^{*}\right)$ and few small-sized regenerating nerve fibers

(arrow) are seen. (c-f) Photomicrographs of drug-treated groups showing alternating areas of weakly stained dilated vacuolated nerve fibers $(*)$, fibers with defective myelination

(arrow head) alternating with well myelinated (double arrow), and small-sized remyelinated nerve fibers (arrow),

(c) quercetin-treated subgroup, ( d) pioglitazone-treated subgroup, (e) metformin-treated subgroup, (f) dapagliflozintreated subgroup osmic stain Mic Mag*400

sham group on same days), whereas, the quercetin-, metformin-, dapagliflozin-, and pioglitazone-treated groups showed statistically significant increase in the mean latency to fall compared to those of the EB control group both in the $7^{\text {th }}$ and $21^{\text {th }}$ days $\left(\mathrm{p}<0.001^{*}\right)$ (Fig. 1). It is also evidenced in foot fault test by significant increase in mean number of errors in the EB control group both in the $7^{\text {th }}$ and $21^{\text {st }}$ days (14.38 \pm 3.74 and $14.57 \pm 4.39)$ compared to the sham group in the same days $(1.56 \pm 0.53$ and $1.22 \pm 0.44)$, whereas, the quercetin-, metformin-, dapagliflozin-, and pioglitazone-treated groups showed significant decrease $(\mathrm{p}<0.001)$ in mean number of errors in comparison to the EB control group in the $7^{\text {th }}$ and $21^{\text {st }}$ days of experiment (Fig. 2). In inverted screen test, the EB control group showed a significant reduction in duration that the rats can grasp the screen with mean values in the $7^{\text {th }}$ and $21^{\text {st }}$ days $10.78 \pm 4.89$ and $18.50 \pm 5.55$ compared to $47.89 \pm 8.95$ and $46.50 \pm 7.78$ in the sham group. In contrast, the paw strength was improved in the quercetin-, metformin-, dapagliflozin-, and pioglitazone-treated groups by the significant increase in mean duration that the rats can grasp the screen $(\mathrm{p}<0.001)$ when compared to the EB control group on the $7^{\text {th }}$ and $21^{\text {st }}$ days (Fig. 3). Moreover, the motor power and fine motor coordination were significantly impaired in the EB control group in beam balance test by increase in foot slippage in the $7^{\text {th }}$ and $21^{\text {st }}$ days $(0.76 \pm 0.15$ and $0.56 \pm 0.10)$ in comparison to the sham group $(0.16 \pm 0.05$ and $0.16 \pm 0.07)$. On the other hand, quercetin-,

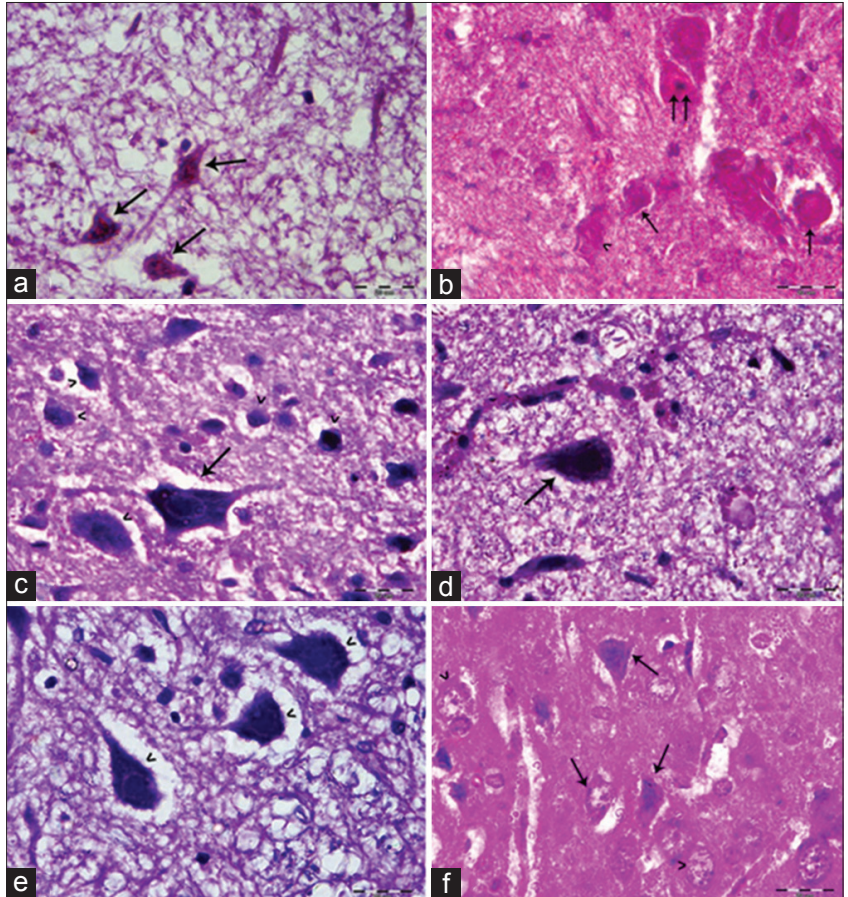

Fig. 7: Photomicrographs of pontine tissue showing: (a) Sham group rat's pyramidal neurons with classical perikaryon with regular triangular outlines and large centrally located vesicular nuclei (arrow). (b) Ethidium bromide subgroup's neurons with

swollen perikaryon, ill-defined, or short dendrites (arrow).

Some nuclei are fragmented $\left({ }^{\wedge}\right)$ or pyknotic (double arrow). The interstitial ground substance is highly vacuolated. (c-f) Different treated groups showing alternative classical neurons (arrow)

and degenerated ones $\left({ }^{\wedge}\right)$. (c) Quercetin-treated subgroup,

(d) pioglitazone-treated subgroup, (e) metformin-treated subgroup, (f) dapagliflozin-treated subgroup hematoxylin and eosin Stain Mic Mag*10,000

metformin-, dapagliflozin-, and pioglitazone-treated groups showed significant improvement in motor performance $(\mathrm{p}<0.001)$ on the $7^{\text {th }}$ and $21^{\text {st }}$ days in comparison to the EB control group (Fig. 4)

Effect of different treated drugs on LINGO-1 and MBP mRNAs expression in pontine tissue

EB injection resulted in upregulation in LINGO-1 mRNA expression in pontine tissue of the EB control group to a significant level when compared to the sham group on the $21^{\text {st }}$ day. In contrast, quercetin, metformin, dapagliflozin, and pioglitazone treatment showed significant downregulation in the level of LINGO-1 mRNA expression when compared to the EB control group on the $21^{\text {st }}$ day (Fig. 5a). Moreover, the level of expression of MBP was significantly upregulated in the quercetin-, metformin-, and pioglitazone-treated groups after the $21^{\text {st }}$ day of experiment when compared to EB control group (Fig. 5b).

\section{Histological results}

Examination of osmic stained pontine white matter of sham rats showed longitudinal and transverse sections of heavily myelinated nerve fibers. The myelin appeared with uniform densely stained black color with regular oval lines and minor spaces in between (Fig. 6a)

Examination of the pontine white matter of the EB control group revealed wide areas of demyelinated nerve fibers. They appeared pale stained, swollen, vacuolated with irregular oval lines and reduced spaces in between. Few small-sized regenerating nerve fibers are present in between wider areas of dissolution demyelinated nerve fibers (Fig. 6b). 
Examination of the pontine white matter of different drug-treated groups revealed different ratios of degenerative and regenerative signs. Degeneration reflected by weakly stained pale irregular degenerated nerve fibers, vacuolation, and incomplete myelination which was more manifested on metformin and pioglitazone, respectively. On the other hand, regeneration was reflected by increased number of small-sized regenerating myelinated nerve fibers alternating with bundles of wellmyelinated nerve fibers. This was more manifested in dapagliflozin and quercetin, respectively (Fig. 6c-f).

The microscopic examination of $\mathrm{H}$ and $\mathrm{E}$ stained pontine cortices of sham rats revealed the classical structure of neuronal architecture. The perikaryon of pyramidal cells showed typical triangular cell borders with regular outline and well-organized dendrites. Their nuclei were large vesicular and centrally located (Fig. 7a)

Examination of cortices of the EB control group revealed widespread degenerative changes reflected on multiple swollen fusiform perikarya with ill-defined borders and absence or shortening of most dendrites. Some of their nuclei appeared fragmented, marginated, or pyknotic. The neuropil in between was highly vacuolated (Fig. 7b).

Administration of the different tested drugs revealed considerable protective effect and ameliorated the degenerative effect of MS to variable degrees with decreased degenerated neurons and reestablishment of cerebral neuronal architecture which was more evident in both dapagliflozin and quercetin followed by pioglitazone and the least with metformin (Fig. 7c-f).

\section{DISCUSSION}

Enhancing the regeneration of myelin sheaths in the CNS has been identified as an important therapeutic target to overcome the consequences of persistent demyelination.

Like all repair processes, the efficiency of the remyelination process decreases with age. Thus, failure of remyelination plays a major role in the progressive neurodegeneration process of MS [30].

Direct injection of EB has offered a simple and reproducible model for studying the biology of remyelination and the repair process [7]. Furthermore, it was a good choice for the behavioral tests due to the delayed action, separating the surgical alterations from the demyelination changes [31].

In the present research, EB injection results in a decrease in locomotor ability of the rats with symptoms including incoordination, muscle weakness, and paralysis as evidenced by rotarod test, foot fault test, beam balance test, and inverted screen test. These findings may be due to demyelination of nerve fibers leading to the impaired conduction of nerve impulses and were evident by the presence of wide areas of demyelinated nerve fibers on pontine white matter of osmic stain sections. Such defects have been correlated to oligodendrocyte loss and, consequently, to the demyelination caused by EB [32].

These findings were consisting of Beckmann et al. work, in which there are an increased number of failures in the beam walking test and increased number of errors on the foot fault test [14].

Furthermore, EB injection resulted in a significant increase in the level of expression of LINGO-1 mRNA expression versus the treated groups. LINGO-1 is selectively expressed in the CNS on both neurons and oligodendrocyte precursor cells (OPCs) and its expression is regulated in the normal CNS, but it is upregulated in human or rat models of neurodegenerative diseases. It has an important role in regulating neuronal survival, axon regeneration, and the time of oligodendrocyte and neuron interactions for myelination during development and disease state [33].
The pontine MBP mRNA expression in EB demyelinated group was significantly decreased after 21 days of experiment in comparison to the treated groups. Our study is in line with Salem et al. found that the expression of MBP in the hippocampus was significantly decreased in the EB-treated group when compared to sham-operated animals [34].

MBP is the second most abundant myelin protein after the proteolipid protein that constitutes the myelin sheath [35]. MBP is expressed in myelinating cells, both immature and mature oligodendrocytes so its expression can be regarded as activity or presence of these cells [36].

Quercetin treatment after EB demyelination resulted in considerable protective effect and ameliorated the degenerative effect of MS to variable degrees with decreased degenerated neurons. This result is in line with Beckmann et al., in which quercetin treatment after EB injection resulted in similar behavioral results to the control in the beam walking test and in the foot fault test [35]. Although evidence in literature on the usefulness of quercetin in demyelinating disorder is lacking, compelling evidence supports its neuroprotective role.

Priyanga et al. reported a neuroprotective role of quercetin in Parkinson's disease by improving the behavioral abnormalities and restoring the biochemical parameters [37], and this result is in line with the effect of quercetin in our study.

Quercetin improved both cognition performance and myelination in perinatal cerebral hypoxia-ischemia-induced brain injury by promoting the proliferation of OPCs and strengthening survival of oligodendrocytes [38]. It acts by inhibiting intramembranous $\gamma$-secretase, thus interfering with canonical Notch signaling, which leads to enhanced remyelination [3]. Furthermore, it selectively inhibits canonical Wnt signaling and this signaling has been shown to affect remyelination by nuclear translocation of $\beta$-catenin. After translocation in the nucleus, $\beta$-catenin binds to transcription factor 4 , which, in turn, delays myelin repair, a process termed canonical Wnt signaling [39].

Metformin treatment after EB injection showed considerable protective effect and ameliorated the degenerative effect of MS to variable degrees when compared to the EB group. The effect of metformin in our study is in accordance with the study conducted by Chakraborty and Torgal demonstrated that metformin might exhibit a beneficial role in the management of neurodegenerative disorders and its symptoms by its antioxidant effect [40].

Whether it promotes myelin repair in demyelinating diseases remains unclear. Metformin mediates its action by activating AMP-activated protein kinase (AMPK), which plays a central role in regulation of energy homeostasis in cells. Studies have shown that activators of AMPK downregulate inflammation in vitro and in vivo in different animal models [41]. Accumulating evidence suggests that AMPK has a critical role in protecting the brain under pathologic conditions through restoration of the CNS energy balance [42]. This protective effect was documented to AMPK activators due to their immunomodulatory activities and the restoration of blood-brain barrier integrity in EAE animals [43]. In addition, AMPK signaling encourages oligodendrocyte survival and, thus, restores CNS integrity and functions in experimental autoimmune encephalitis animals treated with metformin [44].

Dapagliflozin revealed considerable protective effect and ameliorated the degenerative effect of MS. Although studies in neuroprotective effect of SGLT2 inhibitors are lacking, Paul Millar et al. reported beneficial effects of dapagliflozin on cognitive function, neurogenesis, and synaptic density [45].

Moreover, Abdelsameea and Kabil showed that administration of SGLT2 inhibitors along with cisplatin protects rat from sensory and motor neuropathy with improvement in motor performance on rotarod apparatus and prevents neuronal degeneration as well as enhanced the expression of MBP [46]. Furthermore, Ye et al. reported 
that the anti-inflammatory and anti-fibrosis effects of dapagliflozin are mediated through the activation of AMPK [47].

Pioglitazone treatment revealed considerable protective effect and ameliorated the degenerative effect of MS to variable degrees and reestablishment cerebral neuronal architecture. In line with our results, Klotz et al. in which orally administered pioglitazone ameliorated the clinical course and histopathological features in the experimental autoimmune encephalomyelitis animal model [48]

It is well established that PPAR is transcriptional factors involved in the regulation of lipid and glucose metabolism, cell differentiation, and proliferation. This subfamily of nuclear receptors comprises the members PPAR $\alpha, \operatorname{PPAR} \beta / \delta$, and PPAR $\gamma$ which, after ligand activation, regulate gene transcription by dimerizing with the retinoid $\mathrm{X}$ receptor and acting in specific DNA sequences [49]. PPAR $\gamma$ agonists induce astrocyte and prominently OPC differentiation genes of neural stem cells [50]. PPAR $\gamma$ activators further promote OPC maturation toward myelin-forming oligodendrocytes, increasing MBP expression [51]

The beneficial effects of the studied drugs were explained by their effect on LIGO-1 and MBP expression, as the LIGO-1 and MBP had important roles in MS pathogenesis.

\section{CONCLUSION}

From the result of this study, it could be concluded that quercetin, metformin, pioglitazone, and dapagliflozin might have beneficial role in the treatment of neurodegenerative disorders ameliorated the degenerative effect of MS to variable degrees with decreased degenerated neurons and reestablishment cerebral neuronal architecture.

\section{ACKNOWLEDGMENTS}

The author of this manuscript would like to express the deepest gratitude to all who participate in this research.

\section{FUNDING INFORMATION}

This research was supported by Alexandria University Research Award Center. The Alexandria University Research Award Center had no further role in the study.

Authors have full control of all primary data and agree to allow the journal to review data if requested.

\section{AUTHORS' CONTRIBUTIONS}

The author declares that this work was done by the authors named in this work.

\section{CONFLICTS OF INTEREST}

The authors declare that they have no competing interests and certify hereby that this work has never been published.

\section{REFERENCES}

1. Kingwell E, Marriott JJ, Jetté N, Pringsheim T, Makhani N, Morrow SA, et al. Incidence and prevalence of multiple sclerosis in Europe: A systematic review. BMC Neurol 2013;13:128.

2. Pomeroy IM, Jordan EK, Frank JA, Matthews PM, Esiri MM. Focal and diffuse cortical degenerative changes in a marmoset model of multiple sclerosis. Mult Scler 2010;16:537-48.

3. Kremer D, Göttle P, Hartung HP, Küry P. Pushing forward: Remyelination as the new frontier in CNS diseases. Trends Neurosci 2016;39:246-63.

4. Franklin RJ, ffrench-Constant C, Edgar JM, Smith KJ. Neuroprotection and repair in multiple sclerosis. Nat Rev Neurol 2012;8:624-34.

5. Franklin RJ. Why does remyelination fail in multiple sclerosis? Nat Rev Neurosci 2002;3:705-14.

6. Goudarzvand M, Javan M, Mirnajafi-Zadeh J, Mozafari S, Tiraihi T. Vitamins E and D3 attenuate demyelination and potentiate remyelination processes of hippocampal formation of rats following local injection of ethidium bromide. Cell Mol Neurobiol 2010;30:289-99.

7. Blakemore WF. Ethidium bromide induced demyelination in the spinal cord of the cat. Neuropathol Appl Neurobiol 1982;8:365-75.

8. Molina MF, Sanchez-Reus I, Iglesias I, Benedi J. Quercetin, a flavonoid antioxidant, prevents and protects against ethanol-induced oxidative stress in mouse liver. Biol Pharm Bull 2003;26:1398-402.

9. Sharma D, Ojha H, Pathak M, Singh B, Sharma N, Singh A, et al. Spectroscopic and molecular modeling studies of binding mechanism of metformin with bovine serum albumin. J Mol Struct 2016;1118:267-74.

10. Dandona P, Aljada A, Ghanim H, Mohanty P, Tripathy C, Hofmeyer D, et al. Increased plasma concentration of macrophage migration inhibitory factor (MIF) and MIF mRNA in mononuclear cells in the obese and the suppressive action of metformin. J Clin Endocrinol Metab 2004;89:5043-7.

11. Kukidome D, Nishikawa T, Sonoda K, Imoto K, Fujisawa K, Yano M, et al. Activation of AMP-activated protein kinase reduces hyperglycemia-induced mitochondrial reactive oxygen species production and promotes mitochondrial biogenesis in human umbilical vein endothelial cells. Diabetes 2006;55:120-7.

12. Yki-Järvinen H. Thiazolidinediones. N Engl J Med 2004;351:1106-18

13. Bays H. Sodium glucose co-transporter Type 2 (SGLT2) inhibitors: Targeting the kidney to improve glycemic control in diabetes mellitus. Diabetes Ther 2013;4:195-220.

14. Beckmann DV, Carvalho FB, Mazzanti CM, Dos Santos RP, Andrades AO, Aiello G, et al. Neuroprotective role of quercetin in locomotor activities and cholinergic neurotransmission in rats experimentally demyelinated with ethidium bromide. Life Sci 2014;103:79-87.

15. Abdalla FH, Cardoso AM, Pereira LB, Schmatz R, Gonçalves JF, Stefanello N, et al. Neuroprotective effect of quercetin in ectoenzymes and acetylcholinesterase activities in cerebral cortex synaptosomes of cadmium-exposed rats. Mol Cell Biochem 2013;381:1-8.

16. Lee HW, Hakim P, Rabu A, Sani HA. Antidiabetic effect of Gynura procumbens leaves extracts to involve modulation of hepatic carbohydrate metabolism in streptozotocin-induced diabetic rats. J Med Plants Res 2012;6:796-812.

17. Watanabe Y, Nakayama K, Taniuchi N, Horai Y, Kuriyama C, Ueta $\mathrm{K}$, et al. Beneficial effects of canagliflozin in combination with pioglitazone on insulin sensitivity in rodent models of obese Type 2 diabetes. PLoS One 2015;10:e0116851.

18. Mishra B, Pancholi S, Deshmukh A, Panjwani D. Preclinical investigations of a novel dose regimen based on the combination of pioglitazone and Gymnema sylvestre extract. Mol Clin Pharmacol 2012;2:20-33

19. Cetin A, Komai S, Eliava M, Seeburg PH, Osten P. Stereotaxic gene delivery in the rodent brain. Nat Protoc 2006;1:3166-73.

20. Paxinos G, Watson C. The Rat Brain in Stereotaxic Coordinates. $4^{\text {th }}$ ed. San Diego: Academic Press; 1998.

21. Lekic T, Tang J, Zhang JH. A rat model of pontine hemorrhage. Acta Neurochir Suppl 2008;105:135-7.

22. Jeffery ND, Blakemore WF. Locomotor deficits induced by experimental spinal cord demyelination are abolished by spontaneous remyelination. Brain 1997;120 (Pt 1):27-37.

23. Kondziella W. A new method for the measurement of muscle relaxation in white mice. Arch Int Pharmacodyn Ther 1964;152:277-84.

24. Hernandez TD, Schallert T. Seizures and recovery from experimental brain damage. Exp Neurol 1988;102:318-24

25. Deacon RM. Measuring the strength of mice. J Vis Exp 2013;76:2610.

26. Latronico $T$, Branà MT, Gramegna $P$, Fasano A, Di Bari G, Liuzzi GM, et al. Inhibition of myelin-cleaving poteolytic activities by interferon-beta in rat astrocyte cultures. Comparative analysis between gelatinases and calpain-II. PLoS One 2013;8:e49656.

27. Mi S, Lee X, Shao Z, Thill G, Ji B, Relton J, et al. LINGO-1 is a component of the nogo-66 receptor/p75 signaling complex. Nat Neurosci 2004; 7:221-8.

28. Cao J, Wang J, Dwyer JB, Gautier NM, Wang S, Leslie FM, et al. Gestational nicotine exposure modifies myelin gene expression in the brains of adolescent rats with sex differences. Transl Psychiatry 2013;3:e247

29. Zhao L, Guo Y, Ji X, Zhang M. The neuroprotective effect of picroside II via regulating the expression of myelin basic protein after cerebral ischemia injury in rats. BMC Neurosci 2014;15:25.

30. Crawford AH, Chambers C, Franklin RJ. Remyelination: The true regeneration of the central nervous system. J Comp Pathol 2013;149:242-54.

31. Graça DL, Blakemore WF. Delayed remyelination in rat spinal cord 
following ethidium bromide injection. Neuropathol Appl Neurobiol 1986; 12:593-605

32. Bondan EF, Lallo MA, Orsini H, Bentubo HL, Yazbek A, Macrini DJ, et al. Evaluation of locomotor activity after a local induction of toxic demyelination in the brainstem of Wistar rats. Arq Neuropsiquiatr 2006;64:496-503.

33. Mi S, Sandrock A, Miller RH. LINGO-1 and its role in CNS repair. Int J Biochem Cell Biol 2008;40:1971-8.

34. Salem NA, Assaf N, Ismail MF, Khadrawy YA, Samy M. Ozone therapy in ethidium bromide-induced demyelination in rats: Possible protective effect. Cell Mol Neurobiol 2016;36:943-54

35. Benjamins JA, Morell P. Proteins of myelin and their metabolism. Neurochem Res 1978;3:137-74.

36. Baumann N, Pham-Dinh D. Biology of oligodendrocyte and myelin in the mammalian central nervous system. Physiol Rev 2001;81:871-927.

37. Priyanga KS, Vijayalakshmi K, Selvaraj R. Behavioral studies of Wistar rats in rotenone induced model of Parkinson's disease. Int $\mathrm{J}$ Pharm Pharm Sci 2017;9:159-64.

38. Qu X, Qi D, Dong F, Wang B, Guo R, Luo M, et al. Quercetin improves hypoxia-ischemia induced cognitive deficits via promoting remyelination in neonatal rat. Brain Res 2014;1553:31-40.

39. Fancy SP, Chan JR, Baranzini SE, Franklin RJ, Rowitch DH. Myelin regeneration: A recapitulation of development? Annu Rev Neurosci 2011;34:21-43

40. Chakraborty S, Torgal SS. Effect of metformin and simvastatin in diazepam-and sodium nitrite-induced anterograde amnesia in male swiss albino mice. Int J Pharm Pharm Sci 2018;11:18-22.

41. Davis BJ, Xie Z, Viollet B, Zou MH. Activation of the AMP-activated kinase by antidiabetes drug metformin stimulates nitric oxide synthesis in vivo by promoting the association of heat shock protein 90 and endothelial nitric oxide synthase. Diabetes 2006;55:496-505.

42. López M, Varela L, Vázquez MJ, Rodríguez-Cuenca S, González CR, Velagapudi VR, et al. Hypothalamic AMPK and fatty acid metabolism mediate thyroid regulation of energy balance. Nat Med 2010;16:1001-8.

43. Nath N, Khan M, Paintlia MK, Singh I, Hoda MN, Giri S, et al. Metformin attenuated the autoimmune disease of the central nervous system in animal models of multiple sclerosis. J Immunol 2009; 182:8005-14

44. Paintlia AS, Paintlia MK, Mohan S, Singh AK, Singh I. AMP-activated protein kinase signaling protects oligodendrocytes that restore central nervous system functions in an experimental autoimmune encephalomyelitis model. Am J Pathol 2013;183:526-41.

45. Millar P, Pathak N, Parthsarathy V, Bjourson AJ, O'Kane M, Pathak V, et al. Metabolic and neuroprotective effects of dapagliflozin and liraglutide in diabetic mice. J Endocrinol 2017;234:255-67.

46. Abdelsameea AA, Kabil SL. Mitigation of cisplatin-induced peripheral neuropathy by canagliflozin in rats. Naunyn Schmiedebergs Arch Pharmacol 2018;391:945-52.

47. Ye Y, Bajaj M, Yang HC, Perez-Polo JR, Birnbaum Y. SGLT-2 inhibition with dapagliflozin reduces the activation of the nlrp3/ASC inflammasome and attenuates the development of diabetic cardiomyopathy in mice with Type 2 diabetes. Further augmentation of the effects with saxagliptin, a DPP4 inhibitor. Cardiovasc Drugs Ther 2017;31:119-32

48. Klotz L, Schmidt M, Giese T, Sastre M, Knolle P, Klockgether T, et al. Proinflammatory stimulation and pioglitazone treatment regulate peroxisome proliferator-activated receptor gamma levels in peripheral blood mononuclear cells from healthy controls and multiple sclerosis patients. J Immunol 2005; 175:4948-55.

49. Grygiel-Górniak B. Peroxisome proliferator-activated receptors and their ligands: Nutritional and clinical implications - a review. Nutr J 2014;13:17.

50. Kanakasabai S, Pestereva E, Chearwae W, Gupta SK, Ansari S, Bright JJ, et al. PPAR $\gamma$ agonists promote oligodendrocyte differentiation of neural stem cells by modulating stemness and differentiation genes. PLoS One 2012; 7:e50500.

51. De Nuccio C, Bernardo A, De Simone R, Mancuso E, Magnaghi V, Visentin S, et al. Peroxisome proliferator-activated receptor $\gamma$ agonists accelerate oligodendrocyte maturation and influence mitochondrial functions and oscillatory $\mathrm{ca}(2+)$ waves. J Neuropathol Exp Neurol 2011;70:900-12 